\title{
Preparation of Spherical Granules of Dolomite Kiln Dust as Gas Adsorbent
}

\author{
Young-Hoon Choi*, Jae-Hoon Huh**, Shin-Haeng Lee ${ }^{* * * *}$, Choon Han $* * *$, and Ji-Whan Ahn $* * * *, t$ \\ *Dept. of R\&D Team, Daesung Mining Development Inc., Yeongwol 33058, Korea \\ **Dept. of R\&D Team, Hanil Cement Corp., Danyang 27003, Korea \\ ***Dept. of Chemical Engineering, Kwangwoon University, Seoul 01897, Korea \\ ****Mineral Processing Division, Korea Institute of Geosciences and Mineral Resources, Daejeon 34132, Korea \\ (Received December 11, 2015; Revised January 11, January 18, 2016; Accepted January 19, 2016)
}

\begin{abstract}
It is highlighted that increasing the adsorbent surface area on volumetric basis is very important in providing an easy access for gas molecules. Fine particles around $3 \mu \mathrm{m}$ of soft-burned dolomite kiln dust (SB-DKD) were hydrated to wet slurry samples by ball mill process and then placed in a chamber to use spray dryer method. Spherical granules with particle size distribution of 50 60 $\mathrm{\mu m}$ were prepared under the experimental condition with or without addition of a pore-forming agent. The relationship between bead size of the pore-forming agent and size of SB-DKD particles is the most significant factor in preparation of spherical granules with a high porosity. Whereas addition of smaller beads than SB-DKD resulted in almost no change in the surface porosity of spherical granules, addition of larger beads than SB-DKD contributed to obtaining of the particles with both 15 times larger average pore volume and 1 order of magnitude larger porosity. It is considered that spherical granules with improved $\mathrm{N}_{2}$ gas adsorption ability may also be utilized for other atmospheric gas adsorption.
\end{abstract}

Key words : Dolomite, Kiln dust, Granule, Porosity, Gas adsorbent

\section{Introduction}

W hen fine particles are combined with a binder, larger agglomerates with a more uniform form are produced, and the agglomerates formed by such mutual adhesion as this due to electrical attraction of particles surfaces and adhesion characteristics, etc. are called granules. ${ }^{1)}$

Important characteristics here is the formation of pores in granule particles due to the spaces produced between single particles constituting a granule and the spaces produced between combined bodies with particles being continuously connected. ${ }^{2)}$ Porosity here is known to be the major factor affecting physical interaction and chemical reactivity between matters. ${ }^{3,4)}$

To produce many spherical granules having a porous and hollow structure with a size of a few ten $\mu \mathrm{m}$, various methods such as core-shell method, spray drying method, spray pyrolysis method, self-assembly method, smelting method, polymer sponge method, etc. have been reported. ${ }^{3,5)}$ Among these methods, the spray drying method has advantages of good scale-up properties and cost effectiveness, since the design is relatively simple, the particle size distribution is continuous and reproducible with a relatively low and uniform density accompanied by a high specific surface area,

${ }^{\dagger}$ Corresponding author: Ji-Whan Ahn

E-mail : ahnjw@kigam.re.kr

Tel : +82-42-868-3578 Fax : +82-42-861-3990 and no separate drying process is required. ${ }^{6-8)}$

As described in Fig. 1, the pore size and shape of granules reflect the size and shape of the pore-forming agent which is mixed with. ${ }^{10)}$ Therefore, size and fed amount of the poreforming agent along with selection of a solvent for dissolution of the pore-forming agent are important issues for production of granules having pores of a desired shape and size. ${ }^{9)}$ While the organic pore-forming agents in general use can produce thermal deformation due to process temperatures of the spray drying method, production is carried out generally with the spaces where the pore-forming agent was present to be changed to the pores as is in the process of escaping through thermal decomposition."

As the raw material for production of a porous spherical granule form, soft-burned dolomite kiln dust (to be referred to as SB-DKD hereafter) has been selected. For production of the soft-burned dolomite utilized primarily in steelmak-

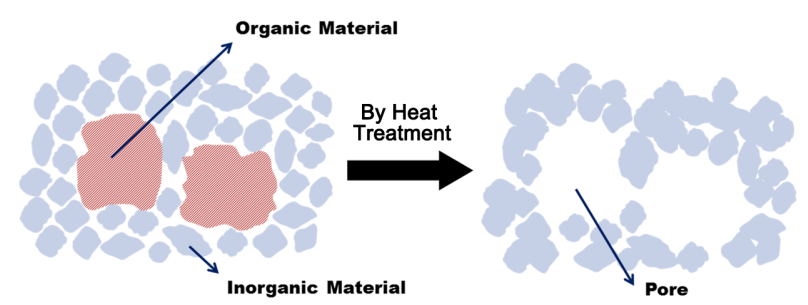

Fig. 1. Pore generation mechanism of spherical granules (inorganic material) through organic pore forming agent (organic material) by heat treatment. ${ }^{10)}$ 
ing industry, etc., shaft kilns are in general use, the firing process of which requires $24 \mathrm{~h}$ and is implemented in the gravity direction as raw stone and anthracite used as a heat source undergo the processes from feeding through firing and air cooling to completion. In this process, degradation occurs due to friction and impact inside the kiln, producing SB-DKD and unburned coal powder. Although the produced amounts are not constant because of combined factors such as microcracks within the raw stone due to impact and stress occurring in the crushing stage, firing extent, season, etc., it accounts for about $30 \%$ of the total production in average. Such products of a fine powder form resulting from firing are not utilized as a product, but most of the produced amounts are temporarily left unattended in air for the purpose of being discarded. Although some of them are sold at a low price for ground stabilization, etc., it is being processed for landfill for mine restoration, etc. together with the fine dust produced in the crushing process of dolomite raw stones.

In the present study, the unutilized SB-DKD that is discarded instead of being industrially utilized was processed to produce porous spherical granules with a low density and high specific surface area, and its utilization possibilities as a high value-added gas adsorbent have been reviewed. After selecting the spray drying method as the major manufacturing process, the raw material in a fine particle form was prepared by its processing into porous spherical granules, and the effects of size of the added pore-forming agent on shape and specific surface area of the final powder were discussed together.

\section{Experimental Procedure}

In the present study, the specimens were employed as a raw material where crushing was executed by overall wet ball milling of SB-DKD without separate classification and impurity removal. As the organic pore-forming agent to prepare porous spherical granules, a slurry was utilized with addition of $30 \mathrm{wt} \%$ of latex solids containing stearic acid of different sizes $(600 \sim 1000 \mu \mathrm{m})$ and polystyrene bead $(0.5$ $\mu \mathrm{m})$. As the binder material, CMC (carboxymethyl cellulose) was used. The conditions for fed slurry employed to utilize the spray drying method are as shown in Table 1. Upon feeding in the process by the spray drying method, stirring was applied continuously to prevent sedimentation of solids within the slurry and to maintain a uniform composition.

As shown in the schematic diagram of Fig. 2, the spray drying method with mounting of a rotary atomizer was utilized. The fed amounts of slurry were controlled to have a

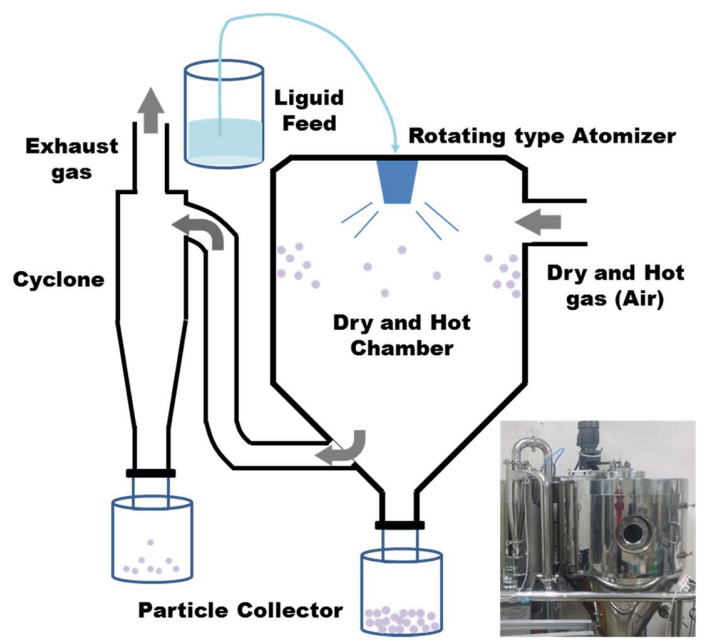

Fig. 2. Schematic illustration of spray dryer process and its equipment.

rate of $17 \mathrm{ml} / \mathrm{min}$ by using a liquid pump of controlled volume, and the rotation speed of the atomizer was set at $2,000 \mathrm{rpm}$. The chamber temperature was set at $230^{\circ} \mathrm{C}$, and air was utilized as the drying gas. The temperature of outlet was affirmed to be about $130 \sim 150^{\circ} \mathrm{C}$. The powder prepared by using the spray drying method was subjected to heat treatment at $450^{\circ} \mathrm{C}$ for complete removal of the added poreforming agent. The overall schematic diagram for powder preparation is as shown in Fig. 3.

For the fine surface structure analysis of the granules prepared per raw material and each condition, Scanning electron microscope (SEM) equipped with Energy dispersive X-ray spectroscopy (EDS) (JEOL, JSM-6380LA) was used, and Particle Analyzer (Malvern, Mastersizer 2000) was employed for the size measurement and analysis of the prepared samples. Brunauer-Emmett-Teller (BET) and BarrettJoyner-Halenda (BJH) analyses (MicrotracBEL, BELSORPMini) were conducted to obtain information on specific surface area, pore size and volume of SB-DKD as the raw material and of the prepared spherical granules.

\section{Results and Discussion}

Shown respectively are pictures of powder shape after conducting only wet ball mill crushing process for the raw material SB-DKD (Fig. 4(a)), and of microstructures after spray drying process for the spherical granules without application of a pore-forming agent (Fig. 4(b)), the spherical granules with addition of polystyrene latex (diameter: $0.5 \mu \mathrm{m}$ ) as the pore-forming agent having smaller particles than SB-

Table 1. Compositions of Slurry according to Pore-Forming Agent

\begin{tabular}{ccccc}
\hline Slurry & Raw Material & Pore Foaming Agent & Binder & Water \\
\hline 1 & $100 \mathrm{~g}$ & $0 \mathrm{~g}$ & $0.25 \mathrm{~g}$ & $450 \mathrm{~g}$ \\
2 & $100 \mathrm{~g}$ & Polystyrene $(0.5 \mu \mathrm{m}) 9 \mathrm{~g}$ & $0.25 \mathrm{~g}$ & $450 \mathrm{~g}$ \\
3 & $100 \mathrm{~g}$ & Stearic Acid $(600 \sim 1,000 \mu \mathrm{m}) 9 \mathrm{~g}$ & $0.25 \mathrm{~g}$ & $450 \mathrm{~g}$ \\
\hline
\end{tabular}




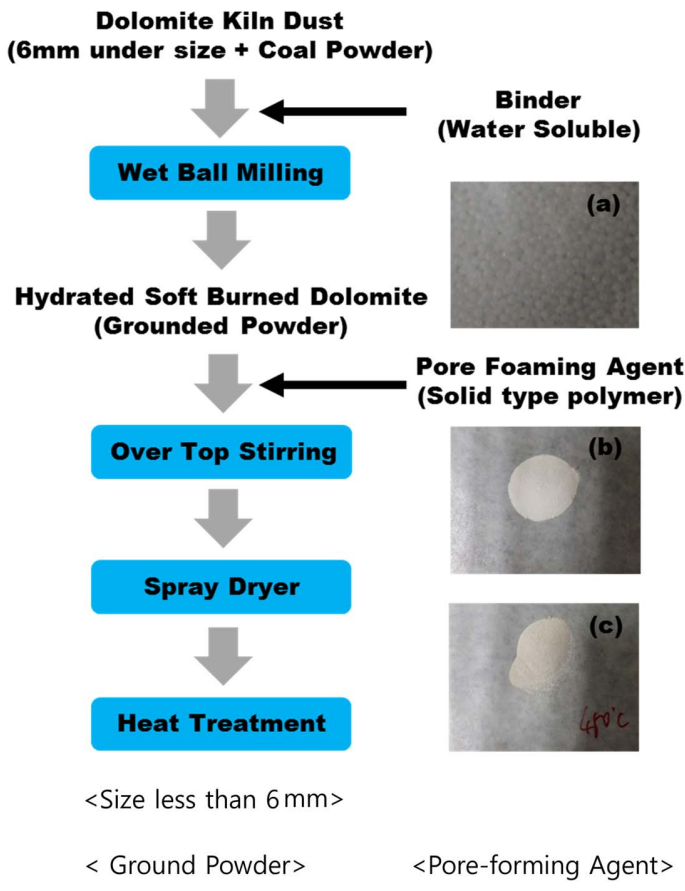

Fig. 3. Schematic diagram of preparation process by spray dryer: optical images of (a) stearic acid beads, (b) spherical granules, (c) heat treated powder $\left(450^{\circ} \mathrm{C}, 2 \mathrm{~h}\right)$ of spherical granules.
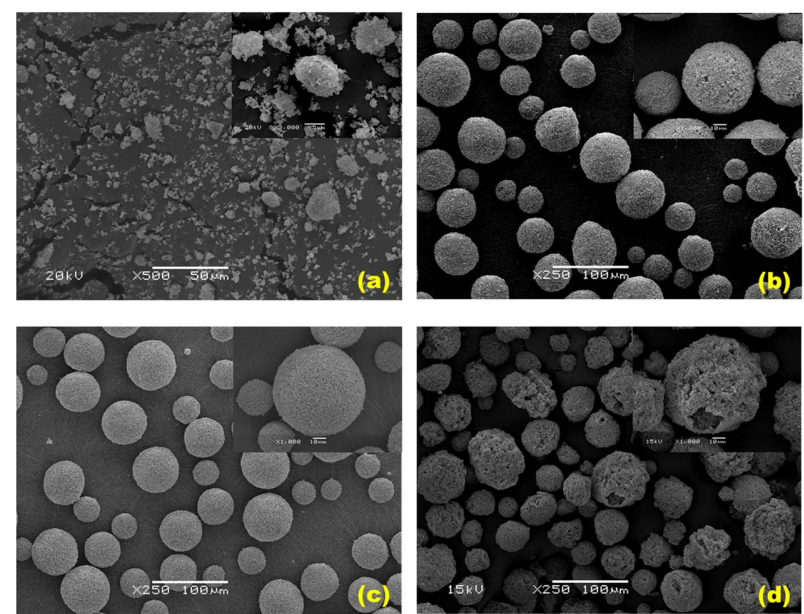

Fig. 4. SEM images of SB-DKD and spherical granule particles identified by added pore-forming agent: (a) SBDKD, (b) no adding, (c) polystyrene latex $0.5 \mu \mathrm{m}$, and (d) stearic acid 600 1,000 $\mu \mathrm{m}$

DKD particles (Fig. 4(c)), spherical granules with addition of stearic acid (diameter: $600 \sim 1000 \mu \mathrm{m}$ ) as the organic poreforming agent having larger particles than SB-DKD particles (Fig. 4(d)). Here, in comparison with the particle size of SBDKD $(3 \mu \mathrm{m})$, stearic acid is $200 \sim 333$ times as large, while polystyrene bead is about $1 / 6$ times as small. SB-DKD existing in the form of fine particles could be affirmed to have been made into more uniform spherical granules through the spray drying method. In the case of the specimens with addition of a pore-forming agent having smaller particle

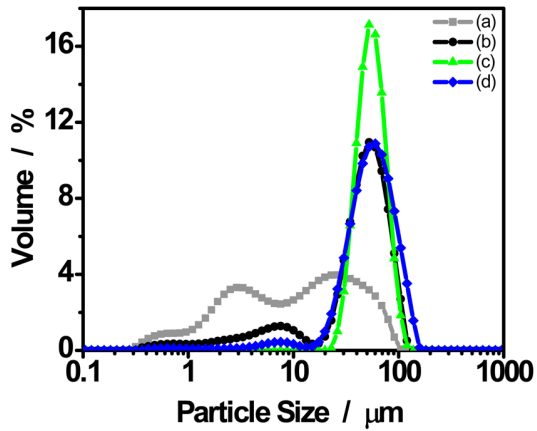

Fig. 5. Particle size analysis of SB-DKD and spherical granule particles identified by with or without poreforming agent: (a) SB-DKD, (b) no adding, (c) polystyrene latex $0.5 \mu \mathrm{m}$, and (d) stearic acid $600 \sim$ $1,000 \mu \mathrm{m}$.

sizes than SB-DKD, no marked difference from the specimens without addition of the pore-forming agent was observed. In addition, whereas pore between particles inside the form agglomerated in a spherical shape are produced partially in the specimens without addition of a poreforming agent, surfaces are formed uniformly in the specimens with application of a pore-forming agent having smaller sizes accompanied by reduction in the pore between particles and the specific surface area. However, since the size of the pore-forming agent was much smaller than that of the raw material, formation of pores in the granules due to deformation and removal of the pore-forming agent could not be clearly affirmed. To the contrary, when a pore-forming agent having a large size compared with the raw material was applied, formation of huge pores with enlargement of practical surface areas along the rough surface curvature could be observed although the form of granules was changed to a distorted spherical shape.

Consequently, it could be seen that selection of a size for the pore-forming agent had a decisive effect on the change in specific surface areas, since the pore-forming agent had a form of being attached onto SB-DKD particles when the size of pore-forming agent was small whereas the opposite mechanism operated when the size of pore-forming agent was large.

To demonstrate uniformity in the size of granules, the particle size distribution results of each specimen after examination of microstructures are shown in Fig. 5. Considering the particle size distribution of SB-DKD (Fig. 5(a)), it may be affirmed that peaks having a similar intensity occurred near $3 \mu \mathrm{m}$ and $30 \mu \mathrm{m}$ while exhibiting a gradual particle size distribution. Such phenomenon is considered attributable to the occurrence of agglomeration by surface combination while the oxide was changed in crystals and shapes into the form of hydroxide by reaction with water as SB-DKD was crushed by wet ball milling. ${ }^{11)}$ Concerning the sizes of spherical granule particles (Figs. 5(b), (c) and (d)) with application of the spray dryer process using SB-DKD particles, it could be affirmed that particles having the same 


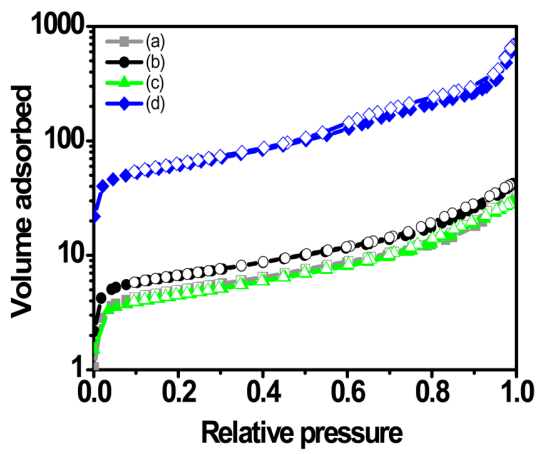

Fig. 6. $\mathrm{N}_{2}$ adsorption/desorption isotherm at $77 \mathrm{~K}$ of SBDKD and spherical granule particles identified by with or without pore-forming agent: (a) SB-DKD, (b) no adding, (c) polystyrene latex $0.5 \mu \mathrm{m}$, and (d) stearic acid $600 \sim 1,000 \mu \mathrm{m}$; unit of $\mathrm{X}$-axis and Y-axis is $\mathrm{P} / \mathrm{P}_{0}$ and $\mathrm{cm}^{3} / \mathrm{g}$, STP, respectively.

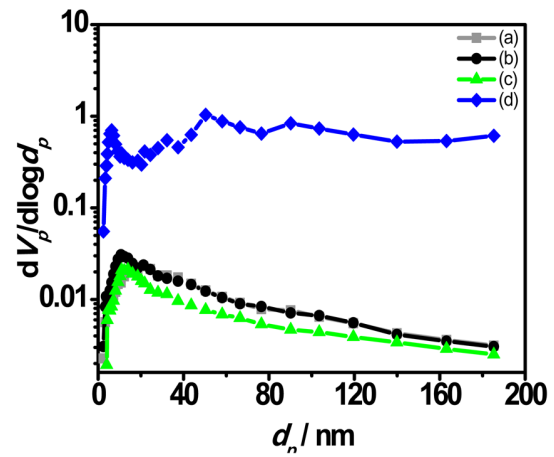

Fig. 7. BJH curve of SB-DKD and spherical granule particles identified by with or without pore-forming agent: (a) SB-DKD, (b) no adding, (c) polystyrene latex $0.5 \mu \mathrm{m}$, and (d) stearic acid $600 \sim 1,000 \mu \mathrm{m}$.

sizes of $50 \sim 60 \mu \mathrm{m}$ had been prepared. This suggests that application of the spray dryer process allows generation of spherical granules with an almost constant particular size, which shows the particle size distribution having a strong intensity, irrespective of application status, type and size change for the pore-forming agent.

In Fig. 6, isothermal adsorption-desorption curves as a function of the adsorbed and desorbed amounts of nitrogen gas are shown, and the magnitudes of specific surface area as a function of the adsorbed amounts of $\mathrm{N}_{2}$ were determined by calculation according to the following equation. ${ }^{12,13)}$

$$
\mathrm{a}_{\mathrm{s}}=\mathrm{n}_{\mathrm{m}} \mathrm{a}_{\mathrm{m}} \mathrm{N}
$$

where $\mathrm{n}_{\mathrm{m}}$ is the single adsorption capacity, $\mathrm{a}_{\mathrm{m}}$ the surface area of the adsorbed gas molecule $\left(\mathrm{N}_{2}: 16.2 \AA\right)$, $\mathrm{N}$ the Avogadro number $\left(6.02 \times 10^{23} / \mathrm{mole}\right)$, and the specific surface area $\left(a_{s}\right)$ value of a sample can be obtained when thus-obtained values are calculated. In the case of Figs. 6 (a), (b) and (c), it can be affirmed that the adsorbed amount of $\mathrm{N}_{2}$ gas in the specimen (d) shows a figure higher by about one order of magnitude compared with other specimens, although a
Table 2. The Measurement Data of BET, Total Pore Volume and Mean Pore Diameter of SB-DKD and Spherical Granule Particles with or without Addition of PoreForming Agent

\begin{tabular}{lccc}
\hline \multicolumn{1}{c}{ Specimen } & $\begin{array}{c}\mathrm{BET} \\
{\left[\mathrm{m}^{2} / \mathrm{g}\right]}\end{array}$ & $\begin{array}{c}\text { Total Pore } \\
\text { Volume } \\
\left(\mathrm{p} / \mathrm{p}_{0}\right) \\
{\left[\mathrm{cm}^{3} / \mathrm{g}\right]}\end{array}$ & $\begin{array}{c}\text { Mean Pore } \\
\text { Diameter } \\
{[\mathrm{nm}]}\end{array}$ \\
\hline (a) Raw Material & 17.696 & 0.053755 & 12.151 \\
(b) No adding & 23.432 & 0.065794 & 11.232 \\
(c) Polystyrene $(0.5 \mu \mathrm{m})$ & 15.618 & 0.045385 & 11.623 \\
(d) Stearic Acid $(600 \sim 1,000 \mu \mathrm{m})$ & 220.75 & 0.9694 & 17.565 \\
\hline
\end{tabular}

large numerical change was not observed in the adsorbed amounts of nitrogen. This may be attributed to the existence of surface shapes with much curvature and of many large pores in the granules.

BJH curves exhibiting pore size distributions for each specimen are shown in Fig. 7. Excluding Fig. 7(d), the remaining specimens show a distribution of relatively many pore sizes in the region less than $20 \mathrm{~nm}$, above which a reduction tendency is exhibited with an increase in the pore sizes. Fig. 7(d) shows a wider distribution of many pores as compared with other specimens.

Shown in Table 2 are the results for BET, pore volume and pore radius per each specimen. BET value for the spherical granules prepared with the pore-forming agent of stearic acid $(600 \sim 1000 \mu \mathrm{m})$ having a larger size than that of SB-DKD was $220.75 \mathrm{~m}^{2} / \mathrm{g}$. This represents an exceptionally high value compared with $15.618 \sim 23.432 \mathrm{~m}^{2} / \mathrm{g}$ for other specimens, with the total pore volume being 15 times as large in average, and the mean pore diameter being also increased by about $5.5 \mathrm{~nm}$ in average. However, the spherical granules prepared without using a pore-forming agent or with application of a pore-forming agent having a small size showed almost the same total pore volume and mean pore diameter, or even a reduction tendency.

Through BET measurements, main information on microor meso-pores could be obtained, and an analysis by using a different measurement method is planned concerning the results related to larger pores such as macro-pores, etc.

\section{Conclusions}

When continuous processes are implemented with wet hydration, ball milling and spray drying method by utilizing unutilized SB-DKD fine particles as the raw material, spherical granules with a uniform size of $50 \sim 60 \mu \mathrm{m}$ can be prepared. When the size of organic pore-forming agent is smaller than that of SB-DKD, the specific surface area of the prepared spherical granules either is reduced or shows no large change as they take a form of adhering onto SB$\mathrm{DKD}$. On the other hand, it was demonstrated that spherical granules with a great improvement in the specific surface areas could be obtained since the completely opposite formation mechanism operated where the SB-DKD adhered 
onto the pore-forming agent to the contrary when the size of organic pore-forming agent was larger than that of the SBDKD. Thus, consideration of the size ratios between an organic pore-forming agent and the raw material had the most decisive effect on the change in specific surface areas. When a pore-forming agent which was 200 333 times as large as the raw material was employed, it could be seen that the mean size of pores was increased by more than 15 times, and the absorbed amount of $\mathrm{N}_{2}$ gas was also increased by more than 10 times. Continuous studies are also planned on adsorption performance of harmful gases such as exhaust gas as a future study subject. Lastly, a contribution to efficient utilization of natural resources such as unutilized SB-DKD, which are industrially discarded or left unattended, is expected to be made through the present study.

\section{Acknowledgments}

The authors are very grateful to the Korea Institute of Energy Technology Evaluation and Planning (KETEP) through the ETI program, Ministry of Trade, Industry and Energy (MOTIE, Project No. 2013T100100021) for financial support of this research.

\section{REFERENCES}

1. F. E. Eichie and A. O. Kudehinbu, "Effect of Particle Size of Granules on Some Mechanical Properties of Paracetamol Tablets," Afr. J. Biotechnol., 8 [21] 5913-16 (2009).

2. U. Schubert and N. Hüsing, "Porous Materials," pp. 305309 in Synthesis of Inorganic Materials, Chapter 6, WileyVCH, Weinheim, 2nd edition, 2005.

3. C. K. Youn, H. M. Lim, S. J. Cha, D. S. Kim, and S. H. Lee, "Preparation of Hollow Silica by Spray Drying of Nano Silica Particles and Its Heat Transfer Property," Kor. J.
Mater. Res., 22 [10] 531-38 (2012).

4. M. W. Han and K. S. Youn, "Quality Characteristics of Spray Drying Microparticulated Calcium after Wet-grinding," Korean J. Food Sci. Technol., 41 [6] 657-61 (2009).

5. D. V. Tuyen and B. T. Lee, "Formation and Characterization of Porous Spherical Biphasic Calcium Phosphate (BCP) Granules Using PCL," Ceram. Int., 37 2043-49 (2011).

6. S. C. Byeon, H. J. Je, and K. S. Hong, "Spray Drying of Ferrite Powders and the Characteristics of the Granule," $J$. Korean Ceram. Soc., 32 [5] 549-58 (1995).

7. M. W. Woo, A. S. Mujumdar, and W. R. W. Daud, "Manipulating Physical Properties of Powder," pp. 37-41 in Spray Drying Technology, Volume 1, Ed., Chapter 2, Published in Singapore, 2010.

8. A. Sosnik and K. P. Seremeta, "Advantages and Challenges of the Spray-Drying Technology for the Production of Pure Drug Particles and Drug-Loaded Polymeric Carriers," Adv. Colloid Interface Sci., 223 40-54 (2015).

9. F. Iskandar, A. B. D. Nandiyanto, W. Widiyastuti, S. Y. Lee, K. Okuyama, and L. Gradon, "Production of Morphology-Controllable Porous Hyaluronic Acid Particles Using a Spray-Drying Method," Acta Biomater., 5 1027-34 (2009).

10. K. Ishizaki, S. Komarneni, and M. Nanko, "Powder Compacts and Green Bodies for Porous Materials," pp. 34-37 in Porous Materials process technology and applications, Chapter 2, Published in Netherlands, 1998.

11. E. Sabah, O. Özdemir, and S. Koltka, "Effect of Ball Mill Grinding Parameters of Hydrated Lime Fine Grinding on Consumed Energy," Adv. Powder Technol., 24 647-52 (2013).

12. B. I. Choi, J. C. Kim, and S. B. Woo, "Results of Round Robin Test for Specific Surface Area," Anal. Sci. Technol., 24 [6] 503-9 (2011).

13. P. B. Balbuena and K. E. Gubbins, "Theoretical Interpretation of Adsorption Behavior of Simple Fluids in Slit Pores," Langmuir, 9 [7] 1801-14 (1993). 